\title{
IMPACT OF THE PLANT RHIZOSPHERE AND AUGMENTATION ON REMEDIATION OF POLYCHLORINATED BIPHENYL CONTAMINATED SOIL
}

\author{
Andrew C. Singer, ${ }^{*} \dagger$ Daniel Smith, $\neq$ William A. Jury, $\dagger$ Khoiviet Hathuc, $\ddagger$ and David E. Crowley $\dagger+$ \\ $\dagger$ Department of Environmental Sciences, $\ddagger$ Microbiology Program, University of California, Riverside, California 92521 USA
}

(Received 4 October 2002; Accepted 21 January 2003)

\begin{abstract}
This study investigated the interactive effects of bioaugmentation, biostimulation, and the rhizosphere during remediation of Aroclor 1242-contaminated soil. Treatments were repeatedly augmented with polychlorinated bipheny (PCB)-degrading bacteria, inducers (carvone and salicylic acid), surfactant (sorbitan trioleate), minimal salts medium in a 20-cm high soil column, or a combination of these elements. Soils containing a single Brassica nigra plant achieved 61\% PCB removal in the 0 to 2 and 2 to $6 \mathrm{~cm}$ depths after 9 weeks of bioaugmentation, whereas only 43 and 14\% PCB removal, respectively, was achieved in unplanted controls. Gas diffusion coefficients of 13.0 and $5.0 \times 10^{-7} \mathrm{~m}^{2} \mathrm{~s}^{-1}$ were calculated from a methane diffusion assay for planted and unplanted soils respectively, indicating the positive effect of plant roots on gas diffusion into the soil. A second, modified column study removed $87,73,63$, and $45 \%$ of PCB after 12 weeks in the 0 to 5,5 to 11,11 to 26 , and 26 to 35 cm depths, respectively, in planted-bioaugmented soils, whereas $65,54,53$, and $47 \%$ of PCB was removed from the planted-minimal salts treatment, respectively. Shifts in the soil microbial community structure were demonstrated by denaturing gradient gel electrophoresis of bacterial 16S ribosomal DNA. Results support that Brassica nigra directly contributed to accelerated PCB removal by increased oxygen diffusion, amendment infiltration, and microbial enrichment.
\end{abstract}

Keywords-Phytoremediation Bioremediation Polychlorinated biphenyl Gas diffusion Denaturing gradient gel electrophoresis

\section{INTRODUCTION}

Of the xenobiotics found world-wide, polychlorinated biphenyls (PCB) are considered amongst the most recalcitrant. Despite nearly 30 years of research on enhancing in situ PCB biodegradation [1,2], the most common method for remediating PCB-contaminated soil still involves excavation, followed by landfilling or incineration [3,4]. In light of the dearth of available remediation options for PCB-contaminated soils, it is surprising that only a few studies have investigated the potential for plants to assist in its removal [5-8].

Research on bioaugmentation and biostimulation of PCBcontaminated soils has recently focused on the important issue of increasing PCB bioavailability through the addition of surfactants and biosurfactants [9-13]. Based on the work of Lajoie et al. [13] and Gilbert and Crowley [14], Singer et al. [15] developed a bioaugmentation approach utilizing a surfactant, sorbitan trioleate, as a semi-selective growth substrate for two PCB-degrading microorganisms, Arthrobacter sp. strain B1B and Ralstonia eutropha $\mathrm{H} 850$. When cultured in the presence of the two compounds that induce cometabolism of PCBs, carvone and salicylic acid, respectively, nearly twice as many PCBs were removed as compared to identically treated nonsurfactant amended soils $[14,15]$. When the same bioaugmentation regimen was applied using earthworms to promote soil mixing, aeration, and enhanced microbial activity, upwards of $65 \%$ PCB removal was achieved in soil to a depth of $6 \mathrm{~cm}$, such that there was $68 \%$ greater PCB removal than in similarly treated unmixed soils without earthworms [16].

The aims of this study were to evaluate the efficacy of black mustard (Brassica nigra) to enhance subsurface PCB degra-

* To whom correspondence may be addressed (acsi@ceh.ac.uk) The current address of A. C. Singer is Centre for Ecology \& Hydrology, Oxford, OX1 3SR, United Kingdom. dation. Brassica nigra was chosen because of its hardiness, fast growth, high biomass, extensive root system, and its proven utility in metal contaminated soils [17]. Amendments of the surfactant sorbitan trioleate and two plant-derived inducers, salicylic acid and carvone, were used in two complementary studies that examined the influence of plants on PCB removal. In study 1 , a gas diffusion assay was employed to evaluate the impact of plant roots on gas diffusion into the soil profilea soil with a greater capacity for oxygen replenishment would foster greater aerobic microbial activity thereby potentially hastening PCB-remediation. In study 2 , modifications were made to the column design used in study 1 to allow for investigation into the limiting role of oxygen on PCB degradation; evaluation of the potential for mobilization of PCBs in the leachate; examination of PCB degradation at greater depth; and evaluation of the microbial community at five sampling depths using polymerase chain reaction-denaturing gradient gel electrophoresis (DGGE) of 16S ribosomal DNA.

\section{MATERIALS AND METHODS}

\section{Soil and mesocosm design}

In study $1,5 \mathrm{~kg}$ of air-dry soil (coarse loamy, mixed, thermic Haplic Durixeralf, pH 7.5, 0.21\% carbon, $0.01 \%$ nitrogen) was acquired from the agricultural plots at the University of California at Riverside (Riverside, CA, USA). Five $\mathrm{g}$ of Aroclor 1242 (AccuStandard, New Haven, CT, USA) was dissolved in $275 \mathrm{ml}$ hexane and slowly mixed into $5 \mathrm{~kg}$ of sieved ( $2 \mathrm{~mm}$ ) air-dry soil. The soil was mixed repeatedly over a 5d period to ensure volatilization of hexane and subsequently mixed into an additional $45 \mathrm{~kg}$ of pristine, sieved soil in an electric cement mixer to make a final concentration of $100 \mathrm{mg}$ Aroclor $1242 \mathrm{~kg}^{-1}$ soil. After $4 \mathrm{~d}, 0.600 \mathrm{~kg}$ (dry wt) of the contaminated soil was added to each of 24 polyvinyl chloride 
columns. The polyvinyl chloride column dimensions were 30$\mathrm{cm}$ length by $2.54-\mathrm{cm}$ radius, and contained $405 \mathrm{~cm}^{3}$-volume of contaminated soil with a $5-\mathrm{cm}$ air reservoir above and below the contaminated soil. Approximately $5 \mathrm{~cm}$ of pea gravel was added to the bottom air reservoir of each tube, which was separated from the contaminated soil by glass wool to provide an equal sized upper and lower air reservoir for the gas diffusion study. After preparing the columns, they were allowed to stand for $90 \mathrm{~d}$ in a greenhouse at the University of California $\left(26 \pm 10^{\circ} \mathrm{C}\right)$. One week before the beginning of the study, each column was brought to field capacity $(\theta=0.12)$ with the addition of $140 \mathrm{ml}$ of half-strength minimal salts media (MSM) [18]. The mass of each soil column was noted to assess the extent of water loss between each soil amendment, and to determine the volume of amendment to be added.

The column dimensions in study 2 were $45 \mathrm{~cm}$ length by $2.54 \mathrm{~cm}$ radius, with $709 \mathrm{~cm}^{3}$ of contaminated soil, overlying a pristine soil layer that was separated from the contaminated zone by a layer of glass wool. The pristine soil layer was intended to capture any leachate and minimize gas diffusion through the base of the column, thereby more closely mimicking natural conditions. Each column was filled with approximately $1.50 \mathrm{~kg}$ (dry wt) of soil originating from the same lot used in study 1 after aging for two and one-half years. The soil was aged in closed stainless-steel canisters in a greenhouse at the University of California, Riverside (temperature range $16-36^{\circ} \mathrm{C}$, air-dry). The columns were otherwise prepared identical to those used in study 1 .

\section{Treatment regimen}

Treatments in study 1 consisted of columns with and without plants, which received one of three different amendments. The first treatment employed bioaugmentation with Ralstonia eutropha H850 (NRRLB-15940) and Rhodococcus sp. ACS. Due to the particular catabolic limitations and congener specificity of PCB-degrading bacteria $[19,20]$, and the wide-range of congeners seen in Aroclor PCB mixtures, it has been suggested a coinoculum approach would achieve more comprehensive PCB degradation [15,21]. The gram-negative strain $R$. eutropha $\mathrm{H} 850$ and the gram-positive strain Rhodococcus sp. ACS have been previously shown to readily degrade PCBs, in particular, after induction by the plant-derived inducing compounds salicylic acid and carvone $[15,22]$. The strains also have been shown to grow readily on the surfactant, sorbitan trioleate, which improves PCB bioavailability and biotransformation in soils $[15,16]$. The bacterial cultures were maintained and prepared as previously described [16]. The Rhodococcus sp. ACS culture contained $100 \mathrm{mg} / \mathrm{L}$ carvone, and $1,000 \mathrm{mg} / \mathrm{L}$ sorbitan trioleate dissolved in MSM. The $R$. eutropha $\mathrm{H} 850$ culture contained $500 \mathrm{mg} / \mathrm{L}$ salicylic acid and $1,000 \mathrm{mg} / \mathrm{L}$ sorbitan trioleate dissolved in MSM. An additional $50 \mu \mathrm{l}$ of sorbitan trioleate was added to each 100-ml culture prior to application, replacing the depleted surfactant, thereby ensuring sufficient surfactant for desorbing PCBs. After the surfactant was added, the flasks were shaken for $15 \mathrm{~min}$ to allow the sorbitan trioleate to dissolve into the medium. Each PCB degrader was added once a week, alternating the isolates at each of the two applications.

The second of the three treatments was a control for the bioaugmentation treatment, in which soils received $100 \mathrm{mg} / \mathrm{L}$ carvone, 1,000 mg/L sorbitan trioleate, and $500 \mathrm{mg} / \mathrm{L}$ salicylic acid dissolved in MSM. The third treatment investigated the role of essential inorganic nutrients in stimulating PCB bio- degradation. All amendments were made twice weekly for 9 weeks.

Four replicate columns were prepared for each treatment, totaling 24 in all (i.e., 12 planted and 12 unplanted). In addition to the bacteria and surfactant, which were added to the columns twice weekly, water was applied as needed to maintain the soil moisture at an optimal level for plant growth. The columns were maintained in a greenhouse at the University of California Riverside where the average temperature was $26 \pm 10^{\circ} \mathrm{C}$. Planted soils contained a single two-week-old seedling of Brassica nigra $3 \mathrm{~d}$ prior to the first amendment.

Study 2 contained the same treatment regimen as study 1 , plus an additional treatment containing MSM without nitrogen (MSM-N). Since the soil was very low in nitrogen $(0.01 \%)$, a MSM minus nitrogen treatment was added to the study to allow further insight into the potential role of nitrogen-containing plant exudates on microbial activity, diversity and PCB degradation. Four replicate columns were prepared for each treatment, totaling 16 in all. Due to the increased volume of soil, the amendment volumes for study 2 were doubled to 20$\mathrm{ml}$ volumes. The amendments were added twice weekly, and repeated for 12 weeks. With the focus of study 2 being the impact of different treatment regimes on the microbial community structure, the study was carried out in a growth chamber $\left(20^{\circ} \mathrm{C}, 70 \%\right.$ relative humidity, and a light intensity of 500 $\mu \mathrm{E} \mathrm{m^{-2 }} \mathrm{s}^{-1}$ with a 16:8-h day:night cycle), thereby minimizing variations in ambient conditions and plant growth.

\section{Analytical procedure}

In study 1 , soil sampling was conducted $3 \mathrm{~d}$ after the eighteenth amendment ( 9 weeks plus 3 d) by removing the entire soil profile from the polyvinyl chloride pipes and dividing them into three depths, 0 to $2 \mathrm{~cm}, 2$ to $6 \mathrm{~cm}$, and 6 to $20 \mathrm{~cm}$. A 22 -g soil sample was randomly removed from each of the thoroughly mixed depths, placed in a 40-ml glass vial with a polytetrafluoroethylene-lined cap, and stored at $-20^{\circ} \mathrm{C}$ until analysis. Soil samples were extracted and analyzed for PCBs by gas chromatograph-flame ionization detector as previously described [16]. Percent recoveries were generated by comparing the solvent-extractable fraction from the treatment to the solvent-extractable fraction from the original untreated Aroclor 1242-contaminated soil. The soil moisture content at the time of sampling was $4 \%$ at all depths in planted soils, while unplanted soils were between 10 and $12 \%$ water. Soil extractions were normalized to the soil moisture content to account for these discrepancies.

Two replicate columns within each treatment were sampled at 2 depths, 2 to $6 \mathrm{~cm}$ and 6 to $20 \mathrm{~cm}$, for water content and carbon/nitrogen analysis [23]. Forty-mg samples were prepared for total carbon and nitrogen analyses as per manufacturer instructions (Carlo Erba Nitrogen Analyzer Model 1500R/AS 200, Carlo Erba Instruments, Milan, Italy) after being ground into a powder using a mortar grinder (Ratsch Type RM-0, Krefeld, Germany). Plant tissues were carefully removed from the soil profile, divided into the root and shoot tissue, gently washed in deionized water to remove adsorbed soil and stored at $-20^{\circ} \mathrm{C}$ until extraction. The plant tissue was freeze dried and ground into a fine powder in a Wiley mill at which time they were weighed into 2 g portions, and extracted in triplicate $40-\mathrm{ml}$ vials with $10 \mathrm{ml}$ hexane. The solvent extract was removed and passed through a Florisil clean-up cartridge (6 ml LC-Florisil; Supelco, Bellefonte, PA, U.S.A.), that had been preconditioned with hexane. The extract was followed 
with $3 \times 1 \mathrm{ml}$ aliquots of hexane. The hexane fraction was analyzed by gas chromatograph-flame ionization detector as described above after concentration [16].

\section{Gas diffusion assay}

Representative soil columns from the planted and unplanted treatments in study 1 were subjected to a methane diffusion assay that enabled quantification of the effect of plants on gas diffusion into the soil columns. It was postulated that an increase in gas diffusion would enable greater aerobic biotransformation of PCB. The columns were capped tightly with a rubber pipe cap and fitted with two Teflon ${ }^{\circledR}$ septa per cap. A $2.5 \mathrm{~cm}^{3}$ pulse of methane was injected into the bottom of the sealed soil column through the septum, at which time $2.5 \mathrm{~cm}^{3}$ was removed to relieve any pressure buildup. The top and bottom air reservoirs in the soil column were repeatedly sampled with a gas-tight syringe for a 340-min time period and immediately manually injected onto the gas chromatographflame ionization detector (isocratic, $60^{\circ} \mathrm{C}$ ). A gas diffusion coefficient was calculated based on the best fit of a gas diffusion transport model, as previously described [16]. Data from the unplanted column was fitted to the model by assuming zero degradation of methane in the soil during transport. However, the data from the planted column indicated methane depletion over time, necessitating a first-order degradation coefficient to be simultaneously fitted to the data.

\section{Microbial community anlaysis}

The biphenyl-utilizing microbial populations were enumerated from a 1-g soil sample originating from each of the soil depths within each soil column in study 1 [16]; biphenyl is the unchlorinated congener of PCBs. Although biphenyl utilization is not necessarily an indication of a bacterial species' ability to degrade PCBs, all PCB degraders appear to be able to metabolize biphenyl.

To provide an indication of the influence of the different amendments on the indigenous soil microbial population in study 2 , the bacterial community $16 \mathrm{~S}$ ribosomal DNA was extracted and analyzed by DGGE. Soil samples (1g) were processed using a FastPrep bead beater (Bio 101, Vista, CA, USA) for each of the four sample depths $(0-5,5-11,11-26$, $26-35 \mathrm{~cm})$. The total soil DNA was isolated with the Fast DNA kit for soil as described by the manufacturer (Bio 101). The eluted DNA products were stored at $-20^{\circ} \mathrm{C}$ prior to analysis. DNA from each soil sample was subjected to polymerase chain reaction and DGGE as previously described [24].

The DGGE gels were analyzed using Scion Image analysis software (Scion, Frederick, MD, USA). The resulting line profiles for each lane were then analyzed using Peakfit (SPSS Science, Chicago, IL, USA) to determine the band intensities and their positions in the lane relative to the front (Rf). The DNA bands obtained on different gels were normalized using marker DNA run on each gel. After Peakfit analysis, numerical data was exported to an Excel spreadsheet (Microsoft, Redmond, WA, USA) where a summary table (Rf vs intensity) was generated for statistical analyses using Minitab (Minitab, State College, PA, USA). The peak data were subjected to cluster analysis to determine the relatedness of each treatment's microbial community, and to determine the percent similarities in microbial communities between different treatments at each depth $(0-5,5-11,11-26,26-35 \mathrm{~cm})$. The cluster diagram presented in this manuscript was generated using the mean values for DNA profiles from four replicate soil columns per
Table 1. Percent polychlorinated biphenyl (PCB) recovered from soil originating from study $1^{\mathrm{a}}$

\begin{tabular}{lcccc}
\hline & \multicolumn{3}{c}{ Depth (cm) } \\
\cline { 2 - 4 } Treatments & $0-2$ & $3-6$ & $6-20$ & Total $^{\text {b }}$ \\
\hline Planted & & & & \\
Bioaugmented & $39 \mathrm{ACa}$ & $39 \mathrm{Da}$ & $65 \mathrm{Ab}$ & 57 \\
Biostimulated & $63 \mathrm{Ba}$ & $59 \mathrm{CBa}$ & $65 \mathrm{Aa}$ & 64 \\
Minimal salts & $39 \mathrm{Ca}$ & $57 \mathrm{CDEa}$ & $60 \mathrm{Aa}$ & 57 \\
Control & & & & \\
Bioaugmented & $57 \mathrm{ABCa}$ & $86 \mathrm{Ab}$ & $70 \mathrm{Aab}$ & 72 \\
Biostimulated & $49 \mathrm{ABCa}$ & $84 \mathrm{ABb}$ & $79 \mathrm{Aab}$ & 77 \\
Minimal salts & $48 \mathrm{ABCa}$ & $65 \mathrm{BCab}$ & $67 \mathrm{Ab}$ & 65 \\
\hline
\end{tabular}

a Soil PCB removal at the same depth are significantly different $(p>$ 0.05 ) if marked with different uppercase letters (two-factor analysis of variance with repeated measure using Student-Newman-Keuls). The PCB removal values within the same treatment are significantly different $(p<0.05)$ if denoted with different lowercase letters (two factor analysis of variance using Student-Newman-Keuls).

b The total percent PCB removal from treatments was weighted to account for differences in the volume of soil at each depth, as discussed in the text.

treatment to compare the different community profiles at the four soil depths.

\section{RESULTS AND DISCUSSION}

Study 1

Planted treatments resulted in removal of 35 to $61 \%$ of the PCBs to a depth of $20 \mathrm{~cm}$, as compared to 14 to $52 \%$ removal in unplanted soils, irrespective of the treatment and depth (Table 1). No significant differences were detected between planted biostimulated and soils treated only with MSM (39-65\% PCB recovery), and their corresponding unplanted treatments (48-84\% PCB recovery) at any respective depth. Polychlorinated bipheny recoveries in the upper $6 \mathrm{~cm}$ of the planted bioaugmented soil columns (39\% PCB recovery) were significantly lower than PCB recovery in the lower 6 to $20 \mathrm{~cm}$ depth (65\% PCB recovered). Of particular note is the 2 to $6 \mathrm{~cm}$ depth in bioaugmented soils, in which significantly less PCB is recovered in the presence of the plant (61\% removal) than in the unplanted treatment (14\% removal). This result suggests that the plant rhizosphere contributed to PCB removal through enhanced inoculum penetration into the soil profile, likely by means of preferential flow channels generated from roots. Polychlorinated biphenyl removal observed in this study compares quite favorably with similarly treated PCB-contaminated soil in Singer et al. [16], in which earthworms were evaluated for their ability to stimulate PCB degradation. In this instance, the authors demonstrated $66 \%, 65 \%$ and $50 \%$ removal of PCB at depths of 0 to 2, 2 to 6 , and 6 to $20 \mathrm{~cm}$, respectively. Total PCB degradation per soil column was calculated by summing the products of PCB degraded from each of the depths by the percent that that depth contributes to the soil in the column. More specifically, in Study 1 the 0 to $2 \mathrm{~cm}$ depth contributes $10 \%$ to the total volume of soil in the column, while the 2 to $6 \mathrm{~cm}$ depth is twice as long, thus representing $20 \%$ of the soil in the column, and the 6 to $20 \mathrm{~cm}$ depth contributes $70 \%$ of the soil in each column. Planted columns removed more PCBs per soil column (36-43\% removal) than unplanted treatments (23-35\% removal, Table 1 ).

A previous report demonstrated removal of $77 \%$ of Aroclor 1248 in a pot experiment containing eight Medicago sativa 
L. (alfalfa) using a low organic matter soil, whereas unplanted controls removed only $18 \%$ [7]. The same authors conducted a PCB transformation study with two other plants, tall fescue (Festuca arundinacea Schreb.) grass and Sericea lespedeza (Lespedeza cuneata [Dum.-Cours.]) legume species in Aroclor 1248 contaminated soil. In the low organic matter soil, $71 \%$ of PCBs were removed in the Sericea-planted soil, $66 \%$ in the tall-fescue-planted treatment, and $18 \%$ in the unplanted control soil [25]. An additional study demonstrated approximately $45 \%$ PCB removal of industrially-contaminated soil when planted with Medicago sativa L. (alfalfa). The addition of a PCB-degrading rhizobia, Sinorhizobium meliloti, to planted treatments was not shown to improve PCB removal in that study [6]. There was no report of PCB degradation on a depth basis in any of these studies. Due to heterogeneous PCB removal (i.e., greater at the surface where volatilization is higher and lower at depth where oxygen is more limiting), dissimilar pot designs, and different methods of assessing PCB removal, comparisons between previous studies and this study can not be accurately made.

Approximately $6.8 \mathrm{~g}$ of soil was exposed to the atmosphere at the soil surface (to a depth of $0.5 \mathrm{~cm}$ ) representing approximately $24 \%$ of the 0 to $2 \mathrm{~cm}$ depth, and only $1 \%$ of the total soil in the treatment. Therefore, volatilization of PCBs is not likely to affect the interpretation of results with respect to the soil column as a whole, however, it certainly played a role in the fate of PCBs in the uppermost soil layer. A measure of the volatilized PCBs may be found in the PCB content of above-ground plant material [26]. Plant leaf material averaged $2.4 \pm 1.5 \mu \mathrm{g}$ PCB $\mathrm{g}^{-1}$ plant matter (dry wt). The plant stems contained $2.3 \pm 3.0 \mu \mathrm{g}$ PCB g ${ }^{-1}$ plant matter (dry wt), whereas the plant roots yielded the highest values of $12.8 \pm 2.8 \mu \mathrm{g}$ PCB g $\mathrm{g}^{-1}$ plant matter (dry wt). Although recovery of PCBs in the above-ground plant matter is only an indication of the amount of PCBs volatilizing from the soil, the measured values would predict low PCB loss due to volatilization. The upper 0 to $2 \mathrm{~cm}$ and lower 6 to $20 \mathrm{~cm}$ depths in unplanted soils $(57 \%$ and $70 \%$ PCB recovered, respectively) demonstrated significantly more PCB removal than the 2 to $6 \mathrm{~cm}$ depth (86\% PCB recovery). This curiously high $\mathrm{PCB}$ removal at the lowest depth $(6-20 \mathrm{~cm})$ is likely an artifact of the column design. The lower air reservoir containing the pebble layer was likely responsible for enhancing oxygen diffusion and possibly $\mathrm{PCB}$ volatilization. Therefore, PCB removal in the 6 to $20 \mathrm{~cm}$ depth is probably misleadingly higher than would have likely occurred under more natural conditions. However, this occurrence provides evidence for the importance of oxygen in the bioremediation process. An equally important consideration is the possibility of PCB removal due to polymerization to plantorganic matter [27]. Although the soil contained very low organic matter at the outset, analysis of the carbon and nitrogen content of the soils at the termination of the study showed significant deposition of organic matter into the soil. A debate regarding the toxicological significance of the polymerized PCBs might conclude such PCBs as having been removed. An average of $6.0 \pm 2.0$ times more carbon was recovered from the 2 to $6 \mathrm{~cm}$ depth in planted soils $\left(0.55 \pm 0.07 \mathrm{mg} \mathrm{C} \mathrm{g}^{-1}\right.$ soil) than unplanted soils $\left(0.03 \pm 0.03 \mathrm{mg} \mathrm{C}^{-1}\right.$ soil $)$. Soils with plants averaged $2.0 \pm 0.6$ times more carbon $(0.07 \pm$ $0.04 \mathrm{mg} \mathrm{C} \mathrm{g}^{-1}$ soil) in the 6 to $20 \mathrm{~cm}$ depth than soils without plants $\left(0.04 \pm 0.03 \mathrm{mg} \mathrm{C} \mathrm{g}^{-1}\right.$ soil). The soil nitrogen content ranged between the limits of detection 0.0001 and $0.271 \mathrm{mg}$ -

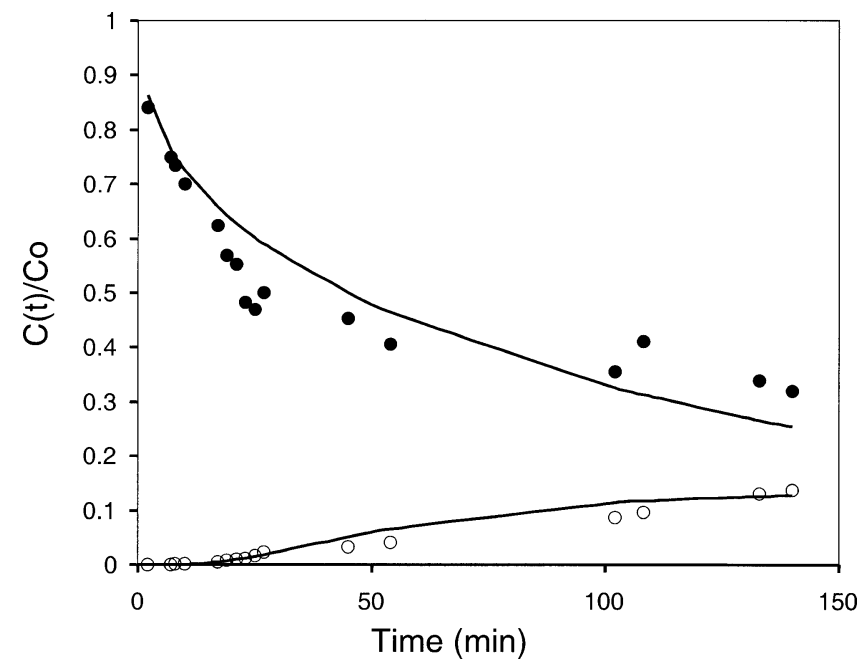

Fig. 1. Gas diffusion in the presence and absence of plants. The ratio of the measured methane concentration $(\mathrm{C}(\mathrm{t}))$ in the inlet (upper series) and outlet (lower series) to the initial methane measurement $(\mathrm{Co})$ is plotted against time $(\mathrm{min})$. The measured (circles) methane concentrations in the planted column were best fit to the model yielding the predicted (line) and a diffusion coefficient (D) of $0.8 \mathrm{~cm}^{2} \mathrm{~min}^{-1}$; unplanted controls yielded $D=0.03 \mathrm{~cm}^{2} \mathrm{~min}^{-1}$.

$\mathrm{N} \mathrm{g}^{-1}$ soil in the planted soils, whereas unplanted soils ranged between the detection limit and $0.120 \mathrm{mg}^{-} \mathrm{N} \mathrm{g}^{-1}$ soil.

The average of three replicate plate counts of colony forming units (CFU) on biphenyl in planted columns ranged from a high of $2.58 \times 10^{9} \mathrm{CFU} \mathrm{g}^{-1}$ at the $0-2 \mathrm{~cm}$ depth, in bioaugmented soils, to a low of $5.6 \times 10^{7} \mathrm{CFU} \mathrm{g}^{-1}$ at the $6-20 \mathrm{~cm}$ depth, in MSM-treated soils. The nonplanted columns followed a similar trend, having the highest biphenyl utilizer density in bioaugmented treatments at the 0 to $2 \mathrm{~cm}$ depth $\left(1.22 \times 10^{9} \mathrm{CFU} \mathrm{g}^{-1}\right)$ and a low in the MSM treatment at the 6 to $20 \mathrm{~cm}$ depth $\left(2.73 \times 10^{7} \mathrm{CFU} \mathrm{g}^{-1}\right)$.

Gas diffusion into the soil column was modeled using a nonconservative methane tracer. The model enabled determination of the diffusion coefficient of planted and unplanted soils. After injection of methane into the lower air reservoir, the methane concentrations in both air reservoirs were repeatedly monitored. Breakthrough of the methane tracer through the $20-\mathrm{cm}$ column was detected after only $2 \mathrm{~min}$ in planted soils (filled circles, Fig. 1), while 340 min was required before breakthrough in soils without plants. Using a gas diffusion model, which generated the best fit curve to the data [16], the diffusion coefficients (D) were calculated to be 0.8 $\mathrm{cm}^{2} \min ^{-1}\left(1.3 \times 10^{-6} \mathrm{~m}^{2} \mathrm{~s}^{-1}\right)$ and $0.03 \mathrm{~cm}^{2} \min ^{-1}(5.0 \times$ $10^{-7} \mathrm{~m}^{2} \mathrm{~s}^{-1}$ ) for planted and unplanted soils, respectively. The diffusion coefficient from planted soils compares favorably to the values obtained in Singer et al. [16], $D=0.27 \mathrm{~cm}^{2} \mathrm{~min}^{-1}$ $\left(4.5 \times 10^{-7} \mathrm{~m}^{2} \mathrm{~s}^{-1}\right)$ which used identical columns containing earthworms instead of plants. Clearly, the presence of plants can greatly influence gas diffusion into a soil profile, upwards of $300 \%$ greater than that previously observed for earthworm bioturbation. The increase in the diffusion coefficient favors a significantly higher rate of soil atmospheric oxygen replacement, and in turn can support a more active aerobic microbial population. Best fit of the diffusion data to the model for the planted treatment necessitated a methane consumption constant (upper series line, Fig. 1), whereas data from the unplanted treatment did not. A methane consumption constant $(\mu)$ of $0.008 \mathrm{~min}^{-1}$ suggested planted soils contained a micro- 
Table 2. Percent polychlorinated biphenyl (PCB) recovered from soil originating from study $2^{\mathrm{a}}$

\begin{tabular}{lccccrrr}
\hline & \multicolumn{5}{c}{ Depth $(\mathrm{cm})$} \\
\cline { 2 - 5 } Treatments & $0-5$ & $5-11$ & $11-26$ & $26-35$ & Leachate & Total $^{\text {b }}$ \\
\hline Bioaugmented & $13 \mathrm{Aa}$ & $27 \mathrm{Aab}$ & $37 \mathrm{Ab}$ & $54 \mathrm{Aab}$ & $10 \mathrm{~A}$ & 36 \\
Biostimulated & $34 \mathrm{Aa}$ & $42 \mathrm{ABab}$ & $49 \mathrm{Aab}$ & $53 \mathrm{Ab}$ & $1 \mathrm{~A}$ & 47 \\
Minimal salts & $35 \mathrm{Ba}$ & $45 \mathrm{Bb}$ & $47 \mathrm{Ab}$ & $53 \mathrm{Ab}$ & $1 \mathrm{~A}$ & 47 \\
Minimal salts minus N & $35 \mathrm{Ba}$ & $50 \mathrm{Bb}$ & $49 \mathrm{Ab}$ & $49 \mathrm{Ab}$ & $2 \mathrm{~A}$ & 47 \\
\hline
\end{tabular}

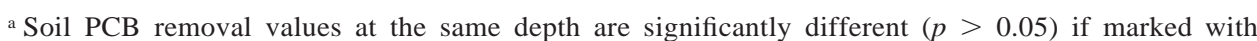
different uppercase letters (two-factor analysis of variance with repeated measures using StudentNewman-Keuls). The PCB removal values within the same treatment are significantly different $(p<$ 0.05 ) if denoted with different lowercase letters (two-factor analysis of variance using Student-NewmanKeuls).

b The total PCB removal from treatments was weighted to account for differences in the volume of soil at each depth, as discussed in the text.

bial community readily capable of transforming methane, unlike unplanted soils. Increased methane consumption was also previously shown in earthworm-treated soils, suggesting either a shift in the population toward methanotrophs, or possibly an increase in ammonia oxidizing bacteria, which have been linked to methane degradation [16,28]. The methane consumption rate constant in earthworm-treated soils was twice that of planted soils $(\mu=0.015)$. This difference may be attributed to the differing sources of nitrogen being deposited in the soil, thereby enriching for dissimilar microbial communities. Unlike earthworm-treated soils, in which urea is the dominant nitrogen-containing excrement [29], planted soils deposit a range of nitrogen-containing compounds, largely complex in nature, originating from dead plant matter and secondary metabolites [30].

\section{Study 2}

All treatments in study 2 contained plants and received one of the following amendments: Bioaugmented, biostimulated, minimal salts medium, and minimal salts medium minus nitrogen. Soil samples from each of the four depths $(0-5,5-11$, 11-26, and $26-35 \mathrm{~cm}$ ) were evaluated for the shifts in the bacterial communities that occurred as a result of the different amendments. The bioaugmented treatment was the most successful treatment in stimulating PCB removal. Polychlorinated biphenyl recoveries in the 0 to 5,5 to 11,11 to 26 , and 26 to $35 \mathrm{~cm}$ depths were $13,27,37$, and $54 \%$, respectively (Table 2). Total PCB removal per soil column was greatest in the bioaugmented treatment (64\% removal) as compared to the three other treatments (53\% for each). Although results of study 1 showed that the plant rhizosphere was considerably more effective in remediating PCB than unplanted controls, results from study 2 suggested bioaugmentation with highly competent PCB-degrading microorganisms can facilitate a greater level of remediation than the rhizosphere alone. In the treatment where $\mathrm{NH}_{4}\left(\mathrm{NO}_{3}\right)_{2}$ was absent from the medium applied to the soil (MSM-N), no significant differences in PCB removal were observed at any of the 4 depths, which is interesting to note in light of the fact that the biphenyl utilizers from the MSM-N treatment $\left(8.43-17.3 \times 10^{7} \mathrm{CFU}^{-1}\right)$ were consistently lower than in all of the other treatments. Biphenyl utilizers in biostimulated soils ranged from 14.5 to $60.3 \times 10^{7}$ CFU $\mathrm{g}^{-1}$, whereas the MSM-treated soil contained between 16.4 and $52.7 \times 10^{7} \mathrm{CFU} \mathrm{\textrm {g } ^ { - 1 }}$. The higher biphenyl utilizer colony counts in bioaugmented soils $\left(83.0-533 \times 10^{7} \mathrm{CFU}^{-1}\right)$ as compared to all other treatments soils suggests there is only a weak positive correlation between the isolation of biphenyl utilizers and PCB degradation. Moreover, there appears to be a strong positive correlation between the input of carbon and nitrogen (i.e, the organic amendments) and culturable biphenyl utilizers.

The leachate from the bioaugmented column averaged 10 $\mu \mathrm{g}$ PCB $\mathrm{g}^{-1}$ soil as compared to the other three treatments, which averaged between 1 to $2 \mu \mathrm{g}$ PCB $\mathrm{g}^{-1}$ soil $(p>0.05)$. Thus, it can be concluded that much of the observed PCB loss can not be attributed to loss in the leachate. Given that the biostimulated treatment contained identical quantities of surfactant as the bioaugmented treatment, one may conclude that sorbitan trioleate alone, as used in this study, did not increase the risk of PCB leaching. However, since greater PCB-containing leachate was found in the bioaugmented treatment, either metabolic breakdown products of sorbitan trioleate enabled greater PCB mobility or an unknown biosurfactant may be uniquely present in this treatment $[12,31]$.

Evidence already presented suggest that the microbial communities within each treatment were different. Evaluation of the microbial communities present on the DGGE provides evidence of clear shifts in the soil microbial population between each of the treatments. The shift in the bacterial community between treatments is consistently greater than the shift in the bacterial community within a soil column between depths (Fig. 2). The 11 to 26 and 26 to $35 \mathrm{~cm}$ depths are consistently more similar to each other within a treatment, most likely because these two depths were the least effected by the amendments, and were more greatly influenced by the plant roots. The 0 to $5 \mathrm{~cm}$ depth was consistently most dissimilar from the rest of the soil depths within a soil column, most likely because it had the greatest exposure to the amendments and oxygen, and was the least influenced by the plant roots. It is important to note that in study 2 , the pristine soil barrier beneath the contaminated soil profile minimized gas diffusion from below, more realistically simulating subsurface conditions. The MSM and MSM-N treatments showed the highest percent similarity in microbial populations between each of the depths within a column. This may be due to the fact that the MSM or MSM$\mathrm{N}$ treatments did not contain any inoculum or carbon sources that could partition preferentially in the upper soil profile, generating fewer differences by depth. Soil that received the bioaugmentation and biostimulation treatments, on the other hand, had measurable changes by depth, likely due to preferential sorption, filtering, and degradation of the amendments in the upper few centimeters. Cluster analysis of the microbial communities within each treatment clearly demonstrated the presence of two distinct groups of bacterial communities, the 


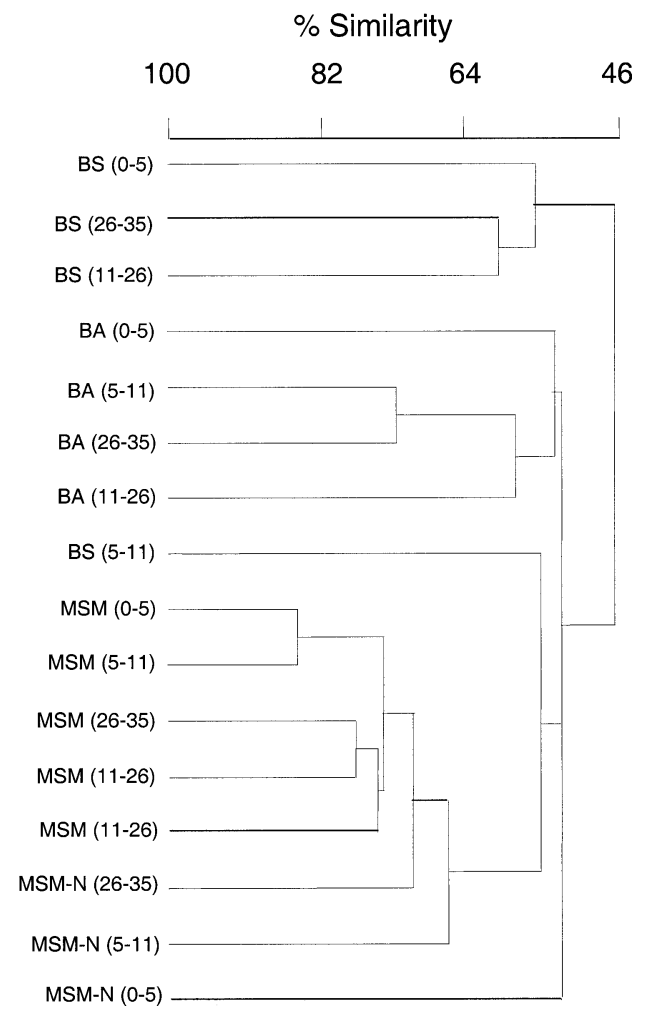

Fig. 2. Cluster analysis of $16 \mathrm{~S}$ ribosomal DNA similarities for bacterial communities in soil treated using bioaugmentation (BA), biostimulation (BS), minimal salts medium (MSM), and minimal salts medium minus nitrogen (MSM-N). Bacterial communities were analyzed at four depths 0 to 5,5 to 11,11 to 26 , and 26 to $36 \mathrm{~cm}$.

bioaugmentation and biostimulation treatments; and the MSM and MSM-N treatments (Fig. 2).

This study demonstrates, using multiple lines of evidence, the effect of plants on PCB remediation of contaminated soils. Studies 1 and 2 provided clear evidence in support of the hypothesis that the rhizosphere is capable of supporting a functionally unique community of microorganisms (e.g., differential methane degradation), that are capable of enhanced PCB removal as compared to unplanted controls. The benefits provided by plants originate from their ability to support higher microbial activity through increased oxygen diffusion and release of exudates into the soil. Results from bioaugmented treatments suggested that plant roots allow increased inoculum penetration, enabling greater subsurface PCB removal. Study 2 further demonstrated that despite clear differences in the indigenous bacterial communities, similar PCB removal efficiencies between treatments were observed. This inconsistency may be explained by the presence of a wide range of PCBdegrading microorganisms that can be found in the rhizosphere of Brassica nigra. In addition to the observed benefit of the rhizosphere effect, bioaugmentation with highly competent PCB-degrading bacteria also enhanced PCB removal to a similar or greater extent than that obtained with plants alone. On the other hand, further research should be conducted to explore whether certain plant species may be more effective than Brassica nigra for enhancing the removal of PCBs by improved gas diffusion, biostimulation of PCB degraders, and increased bioavailability of the contaminant.

Acknowledgement-We thank Katechan Jampachaisri and Ekawan Luepromchai for their invaluable assistance.

\section{REFERENCES}

1. Ahmed M, Focht DD. 1973. Degradation of polychlorinated biphenyls by two species of Achromobacter. Can J Microbiol 19: 47-52.

2. Harkness MR, McDermott JB, Abramowicz DA, Salvo JJ, Flanagan WP, Stephens ML, Mondello FJ, May RJ, Lobos JH, Carroll KM, Brennan MJ, Bracco AA, Fish KM, Warner GL, Wilson PR, Dietrich DK, Lin DT, Morgan DB, Gately WL. 1993. In situ stimulation of aerobic PCB biodegradation in Hudson River sediments. Science 259:503-507.

3. Reisch M. 2002. Solutia Funds PCB Cleanup, Studies, CENEAR, Vol 80. American Chemical Society, Washington DC, USA, p 9.

4. U.S. Environmental Protection Agency. 2002. Hudson River PCBs site New York Record of Decision. Washington, DC.

5. Dzantor EK, Chekol T, Vough LR. 2000. Feasibility of using forage grasses and legumes for phytoremediation of organic pollutants. J Environ Sci Health A 35:1645-1661.

6. Mehmannavaz R, Prasher SO, Ahmad D. 2002. Rhizospheric effects of alfalfa on biotransformation of polychlorinated biphenyls in a contaminated soil augmented with Sinorhizobium meliloti. Process Biochem 37:955-963.

7. Chekol T, Vough LR. 2001. A study of the use of alfalfa (Medicago sativa L.) for phytoremediation of organic contaminants in soil. Remediation 11:89-101.

8. Campanella BF, Bock C, Schroder P. 2002. Phytoremediation to increase the degradation of PCBs and PCDD/Fs: Potential and limitations. Environ Sci Pollut Res Int 9:73-85.

9. Fava F, DiGioia D. 1998. Effects of Triton X-100 and quillaya saponin on the ex situ bioremediation of a chronically polychlorobiphenyl-contaminated soil. Appl Microbiol Biotechnol 50: 623-630.

10. Fava F, Gioia DD. 2000. Soya lecithin effects on the aerobic biodegradation of polychlorinated biphenyls in an artificially contaminated soil. Biotechnol Bioeng 72:177-184.

11. Ghosh MM, Yeom IT, Shi Z, Cox CD, Robinson KG. 1995. Surfactant-enhanced bioremediation of PAH- and PCB-contaminated soils. Proceedings, Third International In Situ and On-Site Bioreclamation Symposium, San Diego, CA, USA, pp 15-23.

12. Golyshin PM, Fredrickson HL, Giuliano L, Rothmel R, Timmis KN, Yakimov MM. 1999. Effect of novel biosurfactants on biodegradation of polychlorinated biphenyls by pure and mixed bacterial cultures. New Microbiol 22:257-267.

13. Lajoie CA, Layton AC, Easter JP, Menn F-M, Sayler GS. 1997. Degradation of nonionic surfactants and polychlorinated biphenyls by recombinant field application vectors. J Ind Microbiol Biotechnol 19:252-262.

14. Gilbert ES, Crowley DE. 1998. Repeated application of carvoneinduced bacteria to enhance biodegradation of polychlorinated biphenyls in soil. Appl Microbiol Biotechnol 50:489-494.

15. Singer AC, Gilbert ES, Luepromchai E, Crowley DE. 2000. Bioremediation of polychlorinated biphenyl-contaminated soil using carvone and surfactant-grown bacteria. Appl Microbiol Biotechnol 54:838-843.

16. Singer AC, Jury W, Luepromchai E, Yahng CS, Crowley DE. 2001. Contribution of earthworms to PCB bioremediation. Soil Biol Biochem 33:765-776.

17. Kumar PBAN, Dushenkov V, Motto H, Raskin I. 1995. Phytoextraction: The use of plants to remove heavy metals from soils. Environ Sci Technol 29:1232-1238.

18. Gilbert ES, Crowley DE. 1997. Plant compounds that induce polychlorinated biphenyl biodegradation by Arthrobacter sp. strain B1B. Appl Environ Microbiol 63:1933-1938.

19. Bedard DL, Haberl ML. 1990. Influence of chlorine substitution pattern on the degradation of polychlorinated biphenyls by eight bacterial strains. Microb Ecol 20:87-102.

20. Bedard DL, Unterman R, Bopp LH, Brennan MJ, Haberl ML, Johnson C. 1986. Rapid assay for screening and characterizing microorganisms for the ability to degrade polychlorinated biphenyls. Appl Environ Microbiol 51:761-768.

21. Viney I, Bewley RJF. 1990. Preliminary studies on the development of a microbiological treatment for polychlorinated biphenyls. Arch Environ Contam Toxicol 19:789-796.

22. Park Y-I, So J-S, Koh S-C. 1999. Induction by carvone of the polychlorinated biphenyl (PCB)-degradative pathway in Alcalig- 
enes eutrophus $\mathrm{H} 850$ and its molecular monitoring. $J$ Microbiol Biotechnol 9:804-810.

23. Rowell DL. 1994. Soil Science: Methods and Applications. Longman Group UK, Essex, UK.

24. Luepromchai E, Singer AC, Yang C-H, Crowley DE. 2002. Interactions of earthworms with indigenous and bioaugmented PCB degrading bacteria. FEMS Microbiol Ecol 41:191-197.

25. Chekol T, Vough LR. 2002. Assessing the phytoremediation potential of tall fescue and sericea lespedeza for organic contaminants in soil. Remediation 12:117-128.

26. Komp P, McLachlan MS. 2000. The kinetics and reversibility of the partitioning of polychlorinated biphenyls between air and ryegrass. Sci Total Environ 250:63-71.
27. Alexander M. 1999. Biodegradation and Bioremediation, 2nd ed. Academic, San Diego, CA, USA.

28. Holmes AJ, Costello A, Lidstrom ME, Murrell JC. 1995. Evidence that particulate methane monooxygenase and ammonia monooxygenase may be evolutionarily related. FEMS Microbiol Lett 132:203-208.

29. Edwards CA, Bohlen PJ. 1996. Biology and Ecology of Earthworms, 3rd ed. Chapman \& Hall, New York, NY, USA.

30. Marschner H. 1995. Mineral Nutrition of Higher Plants. Academic, San Diego, CA, USA.

31. Willumsen PA, Karlson U. 1997. Screening of bacteria, isolated from PAH-contaminated soils, for production of biosurfactants and bioemulsifiers. Biodegradation 7:415-423. 